\title{
Polymer Solid Acid Composite Membranes for Fuel-Cell Applications
}

\author{
Dane A. Boysen, ${ }^{a}$ Calum R. I. Chisholm, ${ }^{a}$ Sossina M. Haile,,${ }^{a} *$ and Sekharipuram R. Narayanan ${ }^{b}, *$ \\ ${ }^{a}$ Department of Materials Science, California Institute of Technology, Pasadena, California 91125, USA \\ ${ }^{b}$ Jet Propulsion Laboratory, Pasadena, California 91109, USA
}

A systematic study of the conductivity of polyvinylidene fluoride (PVDF) and $\mathrm{CsHSO}_{4}$ composites, containing 0 to $100 \% \mathrm{CsHSO}_{4}$, has been carried out. The polymer, with its good mechanical properties, served as a supporting matrix for the high proton conductivity inorganic phase. The conductivity of composites exhibited a sharp increase with temperature at $142^{\circ} \mathrm{C}$, characteristic of the superprotonic phase transition of $\mathrm{CsHSO}_{4}$. At high temperature $\left(160^{\circ} \mathrm{C}\right)$, the dependence of conductivity on vol $\% \mathrm{CsHSO}_{4} \mathrm{was}$ monotonic and revealed a percolation threshold of $\sim 10 \mathrm{vol} \%$. At low temperature $\left(100^{\circ} \mathrm{C}\right)$, a maximum in the conductivity at $\sim 80$ vol \% $\mathrm{CsHSO}_{4}$ was observed. Results of preliminary fuel cell measurements are presented.

(C) 2000 The Electrochemical Society. S0013-4651(00)02-071-1. All rights reserved.

Manuscript submitted February 17, 2000; revised manuscript received June 27, 2000.

Solid acids (or acid salts) are compounds, such as $\mathrm{CsHSO}_{4}$, whose properties are intermediate between those of a normal acid, such as $\mathrm{H}_{2} \mathrm{SO}_{4}$, and a normal salt, such as $\mathrm{Cs}_{2} \mathrm{SO}_{4}$. In general, they are comprised of $\mathrm{XO}_{4}$ anions, where $\mathrm{X}$ can be $\mathrm{S}$, Se, $\mathrm{P}$, or As, etc., which are linked together via $\mathrm{O}-\mathrm{H} . . . \mathrm{O}$ hydrogen bonds. Solid acids in which the cation is a large alkali species (or $\mathrm{NH}_{4}^{+}$) have received increasing attention in recent years because such compounds undergo a transition, the so-called superprotonic transition, at which the conductivity jumps by several orders of magnitude to a value of $10^{-3}$ to $10^{-2} \Omega^{-2}$ $\mathrm{cm}^{-1}$. The transition temperature generally lies between 50 and $150^{\circ} \mathrm{C}$, the activation energy for proton transport in the high-temperature phase is $0.3-0.45 \mathrm{eV}$, and it is generally accepted that proton transport is facilitated by rapid $\mathrm{XO}_{4}$ group reorientations. ${ }^{1}$

Despite their very high proton conductivity, solid acids have generally not been seriously considered for any application, primarily because they are water soluble. In addition, the materials are difficult to process and they have poor mechanical properties (comparable to table salt at room temperature). Moreover, solid acids simply have not come to the attention of the fuel cell, battery, and/or sensor community. The vast majority of studies carried out on solid acids have been performed by those who have been intrigued by the remarkable order-disorder transition that occurs in these compounds, as opposed to those involved in device development.

If one were able to address the limitations of solubility and mechanical robustness, solid acids would be particularly attractive alternatives to perfluorinated sulfonated polymers (e.g., Nafion) for fuel-cell applications. These materials need not be humidified, greatly simplifying fuel-cell system design, they can be operated at temperatures as high as $\sim 200^{\circ} \mathrm{C}$, increasing the $\mathrm{CO}$ tolerance of precious metal catalysts, and they are impermeable to hydrocarbon fluids, rendering them highly applicable for direct methanol fuel cell applications. In the present work, we have prepared composite membranes, comprised of a solid acid and a thermoplastic polymer, which may ultimately combine the high conductivity of the solid acid with the chemical stability and mechanical robustness of the polymer. The solid acid selected for these preliminary investigations is $\mathrm{CsHSO}_{4}$, as the properties of this material are well known (it undergoes a superprotonic transition at $142^{\circ} \mathrm{C}$ from a monoclinic to a tetragonal phase with conductivity $5 \times 10^{-3} \Omega^{-1} \mathrm{~cm}^{-12}$ ) and the polymer selected is polyvinylidene fluoride (PVDF), as it exhibits good chemical stability, desirable mechanical properties, and has an appropriate processing temperature. ${ }^{3}$

\section{Experimental}

$\mathrm{CsHSO}_{4}$ powder was prepared from an aqueous solution of cesium sulfate and sulfuric acid in which the $\mathrm{Cs}_{2} \mathrm{SO}_{4}: \mathrm{H}_{2} \mathrm{SO}_{4}: \mathrm{H}_{2} \mathrm{O}$ molar ratio was fixed at 1:2:12. After dissolution of the components, acetone was added to the solution to induce powder precipitation.

* Electrochemical Society Active Member.
The precipitate was filtered, dried at $60^{\circ} \mathrm{C}$ for $12 \mathrm{~h}$, and stored in a dessicator. The resulting powder was identified by X-ray powder diffraction (Siemens $\mathrm{D} 500$ diffractometer, $\mathrm{Cu} \mathrm{K} \alpha$ radiation) as $\mathrm{CsHSO}_{4}$ phase III $\left(P 2_{1} / c\right){ }^{4}$

Composites of $0-100 \%$ by volume of PVDF $\left(1.78 \mathrm{~g} / \mathrm{cm}^{3}\right)$ to $\mathrm{CsHSO}_{4}\left(3.34 \mathrm{~g} / \mathrm{cm}^{3}\right)$ were prepared in increments of $10 \%$. Mixed powders were ground together in a mortar and pestle for $30 \mathrm{~min}$, then uniaxially hot-pressed at $26 \mathrm{MPa}(3.8 \mathrm{kpsi})$ and $170^{\circ} \mathrm{C}\left(356^{\circ} \mathrm{F}\right)$ for $20 \mathrm{~min}$ to a thickness of $\sim 0.5 \mathrm{~mm}$. This processing temperature lies between the melting point of PVDF $\left(T_{\mathrm{m}}=166^{\circ} \mathrm{C}\right)$ and the decomposition of $\mathrm{CsHSO}_{4}\left(T_{\mathrm{d}}=212^{\circ} \mathrm{C}\right)$. Composites of greater than 30 vol \% PVDF were flexible and relatively durable, whereas samples containing less than $30 \%$ PVDF were brittle and easily broken.

After hot-pressing, the composites were examined again by $\mathrm{X}$-ray diffraction and the microstructures evaluated by electron microscopy using a Camscan Series II scanning electron microscope (SEM). Microscopy samples were prepared by placing in liquid nitrogen and breaking to expose the cross section topology and then sputter-coating with gold to obtain a conductive surface.

A Perkin Elmer DSC7 differential scanning calorimeter (DSC) was used to examine the thermal behavior (structural phase transition and decomposition) of the composites. Samples of $\sim 10 \mathrm{mg}$ were heated under dry flowing argon atmosphere at a heating rate of $5^{\circ} \mathrm{C} / \mathrm{min}$.

The conductivity of each composite was measured using ac impedance spectroscopy. An applied voltage of $1.0 \mathrm{~V}$ and a frequency range of $20 \mathrm{~Hz}-1 \mathrm{MHz}$ were employed using an HP 4284A precision LCR meter. Colloidal silver paste served as electrodes. Absorbed water was removed from the samples by preheating to over $100^{\circ} \mathrm{C}$. AC impedance spectra were collected upon heating and cooling samples at $0.5^{\circ} \mathrm{C} / \mathrm{min}$ under ambient atmosphere. An equivalent circuit model was employed to determine the effective dc resistance from the impedance spectrum at each temperature using the leastsquares refinement program Equivalent Circuit. ${ }^{5}$

In order to examine the potential performance of the composites as fuel-cell membranes, a first-generation membrane electrode assembly (MEA) was constructed and the open-cell voltage (OCV) under hydrogen/oxygen conditions measured. Commercial electrodes (Electrochem EC-2-10) with a platinum loading of $1 \mathrm{mg} / \mathrm{cm}^{2}$ were attached to selected membranes by hot uniaxial pressing at a temperature and pressure of $190^{\circ} \mathrm{C}$ and $68 \mathrm{MPa}(10 \mathrm{kpsi})$, respectively, for $30 \mathrm{~min}$. The MEAs were placed in a fuel-cell test station at $150^{\circ} \mathrm{C}$ for OCV measurements.

\section{Results and Discussion}

The X-ray diffraction pattern obtained from a typical composite is shown in Fig. 1. Diffraction peaks are present both from PVDF, which is expected to be semicrystalline under the processing conditions utilized, and $\mathrm{CsHSO}_{4}$ phase II $\left(P 2_{1} / c\right) .{ }^{6}$ It is well established that upon heating above $57^{\circ} \mathrm{C}^{7} \mathrm{CsHSO}_{4}$ synthesized at room temperature transforms from the metastable phase III to the stable phase II, consistent 


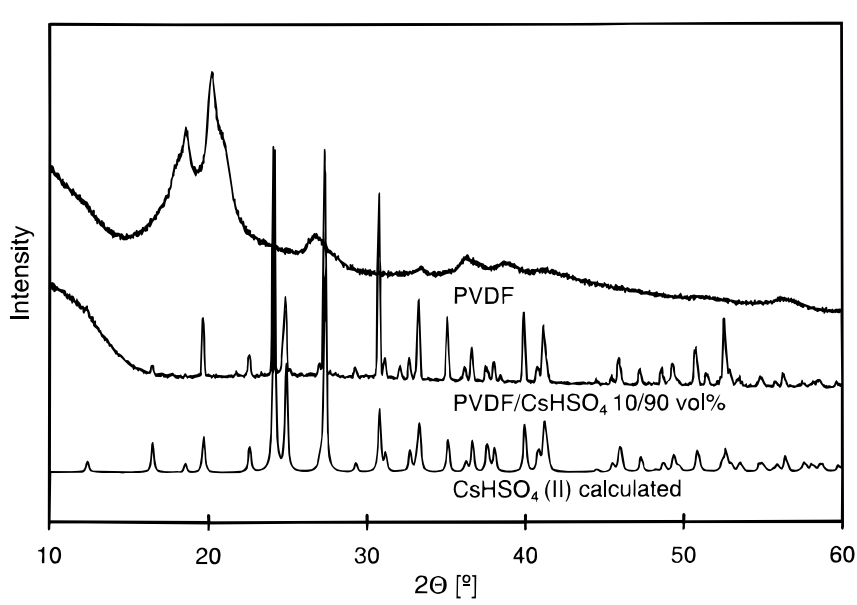

Figure 1. X-ray powder diffraction patterns of PVDF, a PVDF/CsHSO ${ }_{4}$ composite of 90 vol \% $\mathrm{CsHSO}_{4}$ and the calculated pattern for $\mathrm{CsHSO}_{4}$-II. ${ }^{5}$

with the present results. The presence of PVDF and $\mathrm{CsHSO}_{4}$ crystalline phases in the composites demonstrates that for the most part, a complex between these two compounds has not been formed.
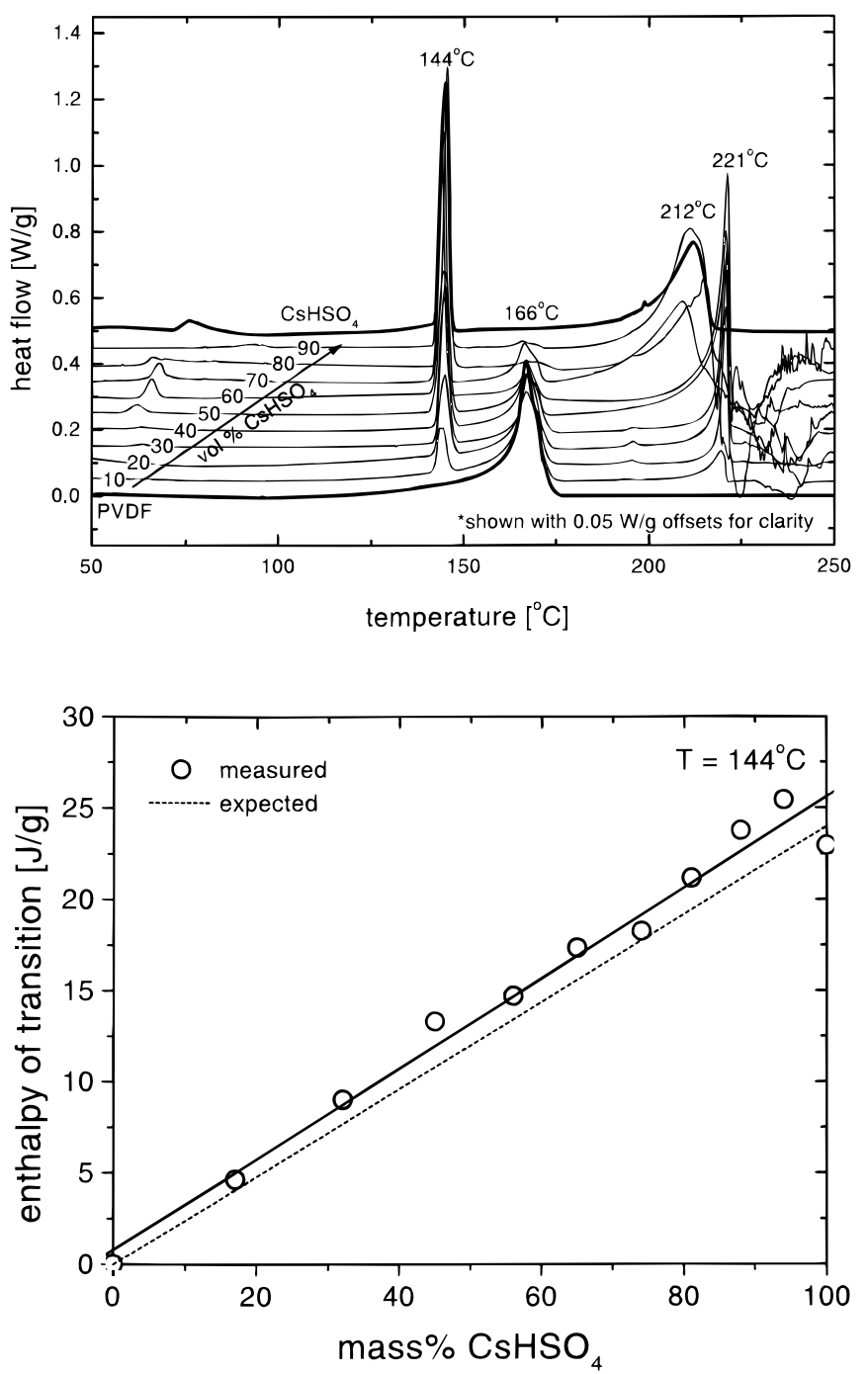

Figure 2. (a, top) DSC traces of $\mathrm{PVDF} / \mathrm{CsHSO}_{4}$ composites of 0-100 vol \% $\mathrm{CsHSO}_{4}$. (b, bottom) The enthalpy of transition at $144^{\circ} \mathrm{C}$ of composites as a function of mass percent $\mathrm{CsHSO}_{4}$.
In Fig. 2 the results of the DSC measurements are presented. The superprotonic transition at $144^{\circ} \mathrm{C}$ is clearly evident in the DSC traces of all samples containing $\mathrm{CsHSO}_{4}$, Fig. $2 \mathrm{a}$. The peak in these data at $166^{\circ} \mathrm{C}$ is due to the melting of PVDF, and the noisy peaks at $\sim 212^{\circ} \mathrm{C}$ and higher are due to the decomposition of $\mathrm{CsHSO}_{4}$. The enthalpy for the superprotonic transition measured here from pure $\mathrm{CsHSO}_{4}$ is $24 \mathrm{~J} / \mathrm{g}$, which is entirely in agreement with the reported value, also $24 \mathrm{~J} / \mathrm{g} .{ }^{8}$ In the composites, the enthalpy of the transition at $144^{\circ} \mathrm{C}$ is linearly proportional to the mass fraction of $\mathrm{CsHSO}_{4}$ with a slope close to the expected, Fig. $2 b$, indicating that all the solid acid transforms to the superprotonic phase.

Typical impedance spectra obtained from a $\mathrm{CsHSO}_{4} / \mathrm{PVDF}$ composite of $40 \mathrm{vol} \% \mathrm{CsHSO}_{4}$ below and above the superprotonic phase transition are shown in Fig. 3 in Nyquist $\left(Z^{\prime} v s Z^{\prime \prime}\right.$ as parametric functions of frequency). In both cases, the effective dc resistance of the composite was determined by fitting the data to an equivalent circuit model composed of a resistor, $R$, and constant phase element, $Q$ (representing the membrane), in parallel with one other, and these, in turn, in series with a second constant phase element (representing the electrode). In some composites the low-temperature impedance spectra exhibited two resolvable arcs. In those cases, the effective dc resistance of the sample was determined from the total presented by the two representative $R Q$ circuits. Whether one or two arcs was present did not correlate to the composite composition; hence, no interpretation is possible without better control of sample processing conditions. At high temperature an electrode response is apparent as a straight line at low frequency, Fig. 3b. For high-conductivity samples, only this electrode response was observable within the measured frequency range, and therefore the effective dc resistance of the sample was extrapolated from the intersection of the electrode response with the real axis.

In Fig. 4, the conductivities determined from the impedance data of six $\mathrm{CsHSO}_{4} / \mathrm{PVDF}$ composites, 0, 20, 40, 60, 80, and $100 \mathrm{vol} \%$ $\mathrm{CsHSO}_{4}$, are plotted in Arrhenius form. For reference, the conductivity of Nafion ${ }^{9,10}$ is also shown. From the results in Fig. 4, it is evident that the $\mathrm{CsHSO}_{4}$ within all the composites undergoes the expected superprotonic transition and that the temperature of the transition is hardly affected by the presence of the polymer. Although the data obtained upon cooling are omitted for clarity, it is also noteworthy that these measurements showed a slight hysteresis in that the reverse transition occurred at $\sim 140^{\circ} \mathrm{C}$. Such behavior is well documented for pure $\mathrm{CsHSO}_{4}{ }^{2}$ and again indicates that the polymer does not interfere with the transformation. In comparison to Nafion, the conductivity of the composites is quite poor at low temperatures.

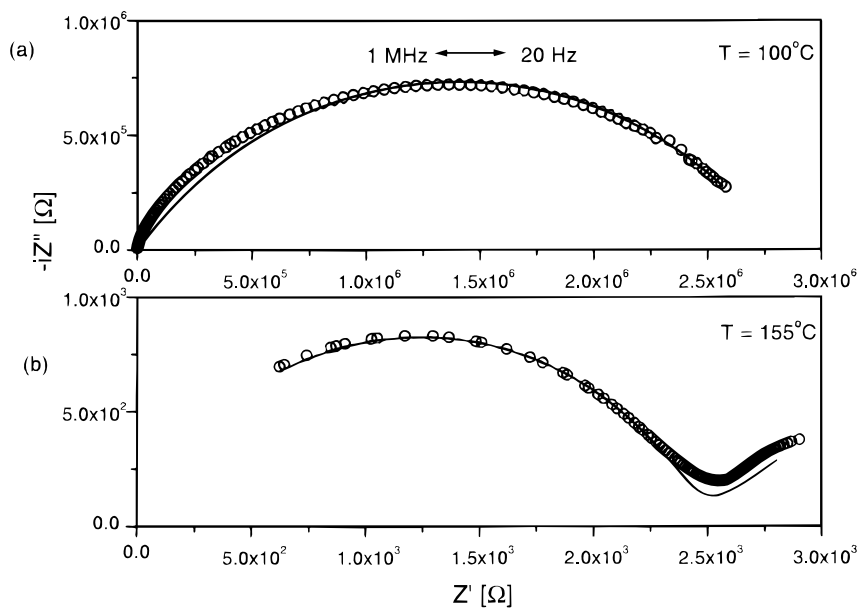

Figure 3. Typical Nyquist plots of $\mathrm{PVDF} / \mathrm{CsHSO}{ }_{4}$ composites of $40 \mathrm{vol} \%$ $\mathrm{CsHSO}_{4}$ (a) before the superprotonic phase transition, $100^{\circ} \mathrm{C}$, and (b) after the transition, $155^{\circ} \mathrm{C}$, used to determine the effective dc resistance. Data fit to an equivalent circuit model composed of a resistor and constant phase element in parallel with one another, and these in turn, in series with a second constant phase element. 


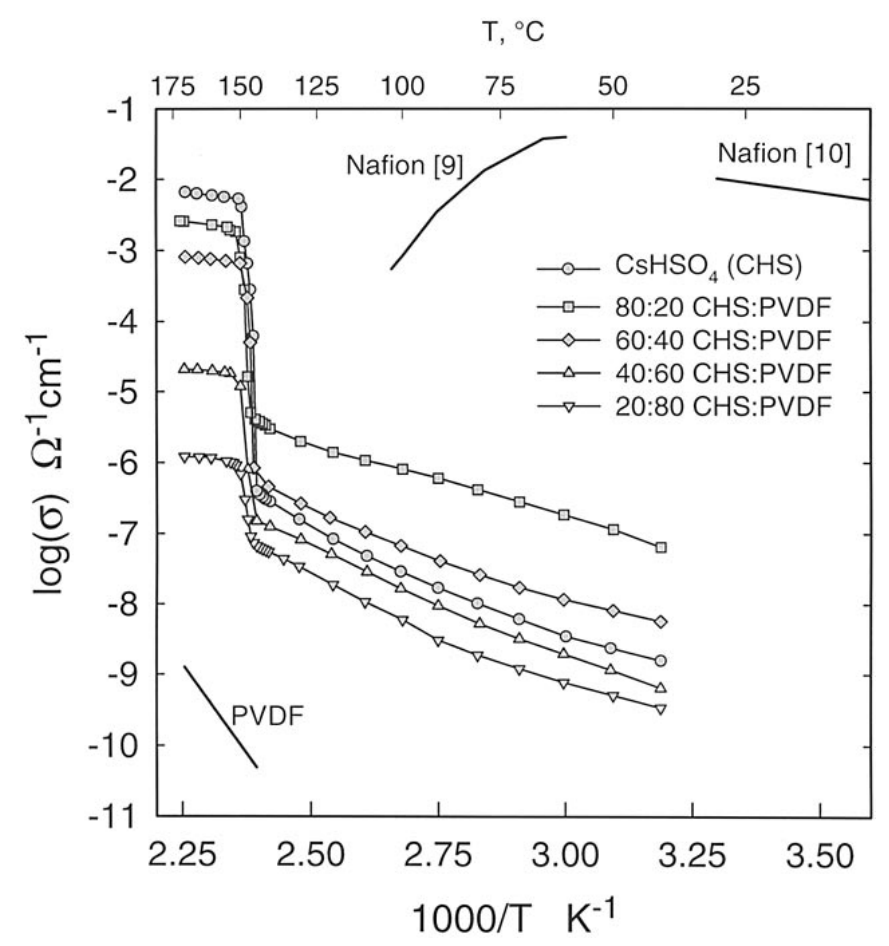

Figure 4. An Arrhenius plot of conductivity of $\mathrm{PVDF} / \mathrm{CsHSO}_{4}$ composites of $0,20,40,60,80$, and $100 \mathrm{vol} \% \mathrm{CsHSO}_{4}$ upon heating. The conductivity of Nafion- $117^{9,10}$ is plotted for comparison. The high-temperature Nafion data were collected under $2 \times 10^{4} \mathrm{~Pa} \mathrm{H}_{2} \mathrm{O}$ partial pressure. ${ }^{9}$ The low-temperature data were collected from a sample with a (fixed) water content of $21 \mathrm{~mol} \mathrm{H}_{2} \mathrm{O}$

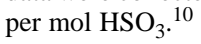

However, the high-temperature conductivity of the high $\mathrm{CsHSO}_{4}$ content composites (in dry atmospheres) is comparable to that of highly humidified Nafion.

In any such composite system, the macroscopic conductivity depends on the conductivities of the individual components, their volume fractions and their spatial distributions. In Fig. 5, the conductivity is plotted as a function of volume fraction $\mathrm{CsHSO}_{4}$ at $160^{\circ} \mathrm{C}$, a temperature above the superprotonic phase transition, and at $100^{\circ} \mathrm{C}$, a temperature below the transition. For a typical percolative system, one expects to see a gradual increase in conductivity $(\sigma)$ with increasing volume fraction of the conductive phase $(\phi)$, then a rapid increase in $\sigma$ in the vicinity of the percolation threshold, $\phi_{c}$, followed by a further gradual increase until $\phi=1$. Furthermore, critical behavior is expected about $\phi_{\mathrm{c}}$. In the case of the high-temperature conductivity, visual inspection reveals that $\phi_{\mathrm{c}}$ lies between 0 and 0.20 , that is, the bulk of the increase in conductivity occurs in this range. As a consequence, the majority of the data reflect a composite system in which the percolation threshold has been exceeded. $\mathrm{Wu}$ and McLachan ${ }^{11}$ have shown that for this regime $\left(\phi>\phi_{\mathrm{c}}\right)$, the conductivity of a mixed system should obey Eq. 1

$$
\sigma_{\mathrm{m}}=\sigma_{\mathrm{c}}\left[\left(\phi-\phi_{\mathrm{c}}\right) /\left(1-\phi_{\mathrm{c}}\right)\right]^{\mathrm{t}} \quad\left[\phi>\phi_{\mathrm{c}}\right]
$$

where $\sigma_{\mathrm{m}}$ is the measured conductivity $\left(\Omega^{-1} \mathrm{~cm}^{-1}\right) ; \sigma_{\mathrm{c}}$ is the conductivity of the conductive phase $\left(\Omega^{-1} \mathrm{~cm}^{-1}\right), \phi$ the volume fraction conductive phase, $\phi_{\mathrm{c}}$ the percolation threshold, and $t$ is the percolation exponent. Fitting the data measured at $160^{\circ} \mathrm{C}$ to this model yields the values $\phi_{\mathrm{c}} \approx 10 \mathrm{vol} \% \mathrm{CsHSO}_{4}$ and $t \approx 4.1$. While the quality of the fit does not encourage detailed analysis of these values, the low percolation limit suggests that the $\mathrm{PVDF}$ and $\mathrm{CsHSO}_{4}$ particles do not form a random mixture but instead that the solid acid particles are preferentially arranged so as to form continuous paths between electrodes at small volume fractions. At $100^{\circ} \mathrm{C}$, the conductivity data do not fit a percolation model but rather show a pronounced maximum at $20 \mathrm{vol} \%$ PVDF. An increase in the conductivity of ionically

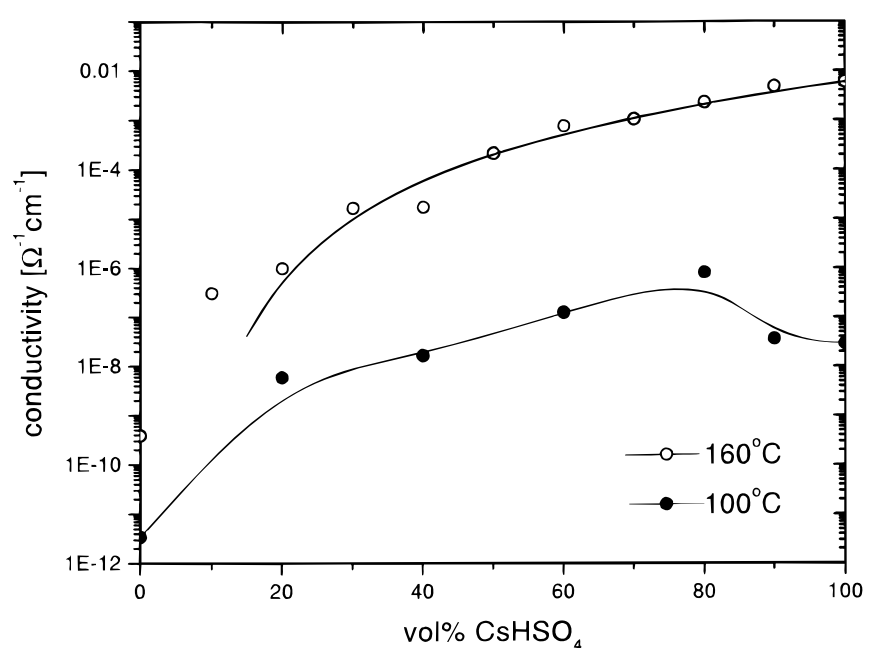

Figure 5. The measured conductivities of $\mathrm{PVDF} / \mathrm{CsHSO}_{4}$ composites as a function of vol $\% \mathrm{CsHSO}_{4}$ at 100 and $160^{\circ} \mathrm{C}$. Data at $160^{\circ} \mathrm{C}$ are fit to the percolation model given by Eq. 1 .

conducting materials with small additions of an insulating phase is a well-known phenomenon and one recently demonstrated in $\mathrm{CsHSO}_{4}$. In particular, $\mathrm{CsHSO}_{4} / \mathrm{SiO}_{2}{ }^{12,13}$ and $\mathrm{CsHSO}_{4} / \mathrm{TiO}_{2}{ }^{14}$ composites containing small volume fractions of the second phase exhibit higher conductivity than pure $\mathrm{CsHSO}_{4}$ at temperatures below the superprotonic phase transition.

Secondary electron images of $\mathrm{CsHSO}_{4} / \mathrm{PVDF}$ composites containing 20 and 80 vol \% $\mathrm{CsHSO}_{4}$ are presented in Fig. 6. The composite containing $20 \mathrm{vol} \% \mathrm{CsHSO}_{4}$, Fig. 6a, contains regions of isolated $\mathrm{CsHSO}_{4}$ particles as well as clusters of $\mathrm{CsHSO}_{4}$. Recall that 20 vol \% $\mathrm{CsHSO}_{4}$ is nominally above the percolation threshold; thus, continuous pathways are expected for this composition. It is possible that small $\mathrm{CsHSO}_{4}$ particles are embedded within the polymer and are not visible in this SEM image. In the composite containing $80 \mathrm{vol} \% \mathrm{CsHSO}_{4}$, the polymer is concentrated in the intergranular regions between $\mathrm{CsHSO}_{4}$ particles. On the basis of the percolation analysis, it must be concluded that the PVDF does not completely coat the solid acid particles.

The OCV obtained from the MEA described above (under a hydrogen/ oxygen configuration and at $150^{\circ} \mathrm{C}$ ) was $0.97 \mathrm{~V}$. Although not as high as the theoretical value of $1.16 \mathrm{~V}$, this OCV is quite encouraging for a first examination, and indeed comparable to open circuit voltages obtained from Nafion. Attempts to draw current from the solid-acid based MEA led to a sharp drop in voltage, much more so than expected simply from the membrane resistance, suggesting that gas flow to or from the electrodes was rate-limiting. A very promising result was that the OCV returned to the initial value after several hours of fuel-cell operation, indicating that $\mathrm{H}_{2} \mathrm{O}$ generated at the cathode had not attacked the membrane. The membrane permeability measured from a $1 \mathrm{~mm}$ thick 50:50 $\mathrm{CsHSO}_{4}: \mathrm{PVDF}$ film was $2.99 \times 10^{27} \mathrm{~mol} / \mathrm{s} \mathrm{cm}^{2}$, a value several times lower than the permeability of Nafion to ambient gases.

If one presumes that it will ultimately be possible to obtain electrodes and catalysts for a solid-acid based MEA that have similar performance to today's Nafion-based MEAs, it is a simple matter to estimate the solid-acid membrane thickness required to obtain fuelcell performance that is competitive with polymeric fuel cells. In the electrolyte-dominated region of a fuel-cell polarization curve, the voltage drop due to membrane resistance, $E_{\mathrm{mem}}(\mathrm{mV})$, is just the membrane area specific resistivity, $\operatorname{ASR}\left(\Omega \mathrm{cm}^{2}\right)$, multiplied by the current density, $i\left(\mathrm{~mA} / \mathrm{cm}^{2}\right)$. The ASR, in turn, is simply $R=t / \sigma$, where $t$ is the membrane thickness and $\sigma$ is the conductivity. A typical Nafion membrane is $\sim 150 \mu \mathrm{m}$ thick and has a conductivity of $\sim 4 \times 10^{-2} \Omega^{-1} \mathrm{~cm}^{-1}$, providing for an ASR of $\sim 0.375 \Omega \mathrm{cm}^{2} .15,16$ To achieve a comparable ASR, a membrane thickness of $\sim 20 \mu \mathrm{m}$ would be required for pure $\mathrm{CsHSO}_{4}\left(\sigma=5.6 \times 10^{-3} \Omega^{-1} \mathrm{~cm}^{-1}\right.$ at 

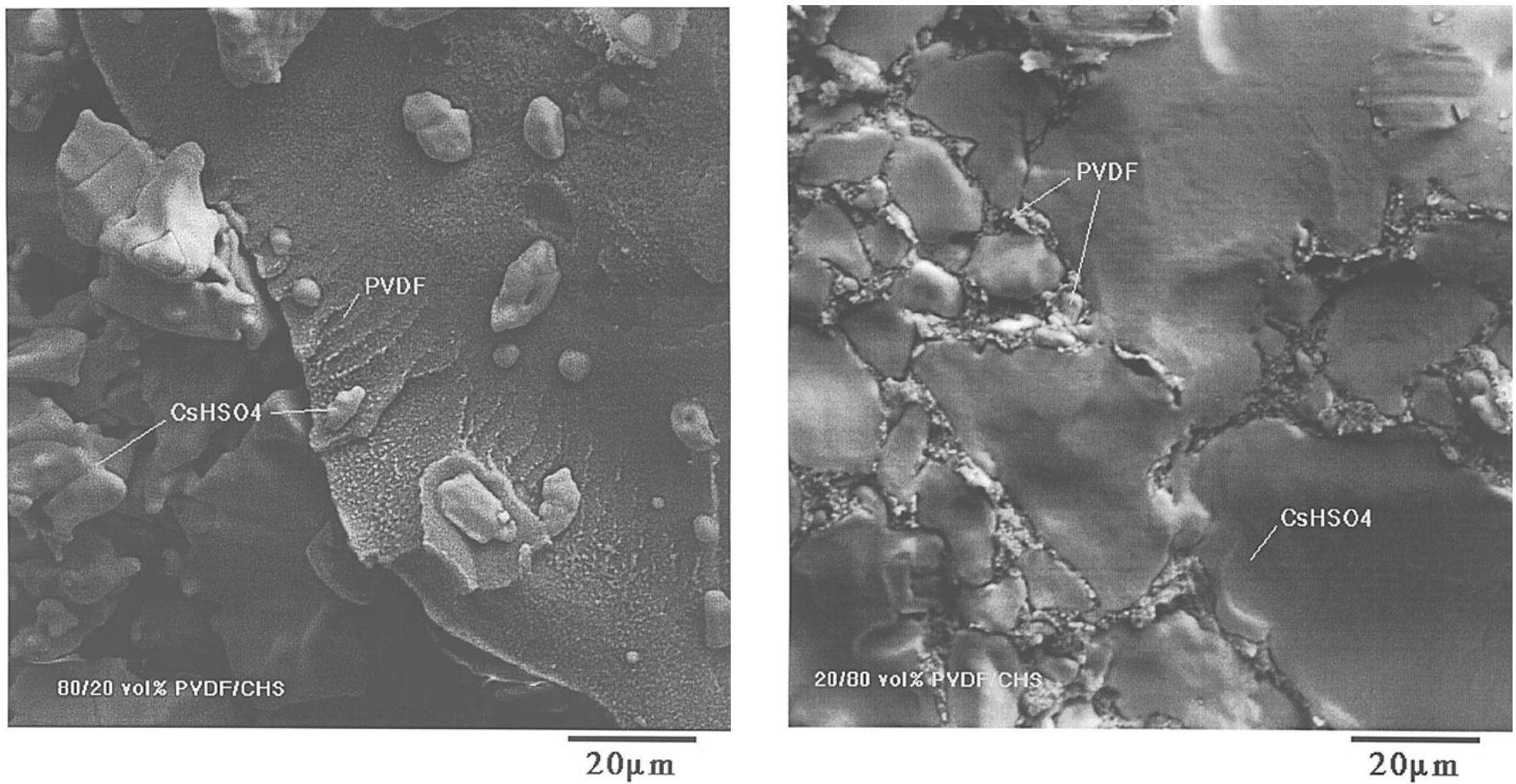

Figure 6. SEM secondary electron images of $\mathrm{PVDF} \mathrm{CsHSO}_{4}$ composites of (a, left) 80 and (b, right) $20 \mathrm{vol} \% \mathrm{PVDF}$.

$150^{\circ} \mathrm{C}$ ) and one of $\sim 6 \mu \mathrm{m}$ would be necessary for a composite containing 20 vol \% PVDF.

\section{Conclusions}

Solid acid/polymer composites represent an attractive alternative to perfluorinated sulfonated polymers for fuel-cell applications. In order to obtain single-cell power densities in ideal hydrogen/oxygen fuel cells that are comparable to that achievable with perfluorinated sulfonated polymers, composite membranes as thin as 5-20 $\mu \mathrm{m}$ would be required, a significant engineering challenge. However, in many applications, improved CO tolerance, elimination of costly and complex humidity and thermal management components, and impermeability to methanol may provide such great advantages that those challenges are addressed. Furthermore, as efforts to develop new solid acids with high conductivity continue, materials with even higher conductivity than $\mathrm{CsHSO}_{4}$ may become available, relaxing the requirement for ultrathin membranes.

California Institute of Technology assisted in meeting the publication costs of this article.

\section{References}

1. K.-D. Kreuer, Chem. Mater, 8, 610 (1996)

2. A. I. Baranov, L. A. Shuvalov, and N. M. Shchagina, JETP Lett., 36, 459 (1982).

3. J. A. Brydson, Plastic Materials, 4th ed., p. 344, Buttersworth Scientific (1982).

4. K. Itoh, T. Ukeda, T. Ozaki, and E. Nakamura, Acta Crystallogr., C46, 358 (1990).

5. B. A. Boukamp, Equivalent Circuit, version 3.97 (1989).

6. Y. Z. Nozik, O. I. Lyakhovitskaya, N. M. Shchagina, and V. A. Sarin, Kristallografiya, 35, 658 (1990).

7. B. Baranowski, M. Friesel, and A. Lundén, Physica A, 156, 353 (1989).

8. M. Friesel, B. Baranowski, and A. Lundén, Solid State Ionics, 35, 91 (1989).

9. J. J. Sumner, S. E. Creager, J. J. Ma, and D. D. DeMarteau, J. Electrochem. Soc., 145, 107 (1998).

10. R. T. C. Slade, A. Hardwick, and P. G. Dickens, Solid State Ionics, 9\&10, 1093 (1983).

11. J. Wu and D. S. McLachlan, Phys. Rev. B, 56, 1236 (1997).

12. V. G. Ponomareva, N. F. Uvarov, G. V. Laurova, and E. F. Hairtdinov, Solid State Ionics, 90, 116 (1990).

13. V. G. Ponomareva, G. V. Laurova, and L. G. Simonova, Solid State Ionics, 118, 317 (1999).

14. V. G. Ponomareva and G. V. Laurova, Solid State Ionics, 106, 137 (1998).

15. C. E. Chamberlin, P. A. Lehman, M. R. Read, and T. G. Herron, Hydrogen Energy Progress X, Proceedings of the 10th World Hydrogen Energy Conference, Cocoa Beach, FL, June 20-24, 1994, Vol. 3, p. 1659, International Association for Hydrogen Energy, FL (1994).

16. J. Kim, S-M. Lee, S. Srinivasan, and C. Chamberlin, J. Electrochem. Soc., 142, 2670 (1995). 